\title{
Introduction to Special Issue on Increasing Participation in Higher Education STEM Programs
}

\author{
Susan Staats $1, * \mathbb{C}$ and Amy Lee ${ }^{2, *}$ \\ 1 College of Education and Human Development, University of Minnesota, 159 Pillsbury Dr. SE, \\ Minneapolis, MN 55455, USA \\ 2 College of Liberal Arts, University of Minnesota, 315 Pillsbury Dr SE, Minneapolis, MN 55455, USA \\ * Correspondence: staats@umn.edu (S.S.); amylee@umn.edu (A.L.)
}

Received: 25 April 2020; Accepted: 2 May 2020; Published: 14 May 2020

\begin{abstract}
This special issue highlights the work of several higher education practitioner-scholars who describe their approaches to facilitating participation in STEM courses and programs. Writing from the standpoint of chemistry, mathematics, and ecology in publicly supported universities, the authors discuss their pedagogical or curricular choices with reference to the broader structures and systemic considerations that sometimes limit and sometimes enable faculty effort. In this editorial, we reflect on the ways in which these authors invoke their own practitioner agency to establish equity-based innovations in higher education STEM settings.
\end{abstract}

Keywords: STEM in higher education; inclusion and equity; diversity; pedagogy; curriculum; teacher development; institutional structures

\section{Introduction}

... close your eyes and think about the usual learning environment of university mathematics

... Does it enable opportunities for students to build narratives around belonging and being included? [1].

In this special issue, we highlight the strategic work of several higher education practitioner-scholars who describe their approaches to disrupting systemic exclusion in STEM courses and programs at their universities. Our authors are working in publicly supported universities in the varied fields of chemistry, mathematics, and ecology, but they have all been able to facilitate and assess important innovations that respond thoughtfully to structural barriers at multiple levels. Through this issue, we wish to open space for us to speak to each other, to share our models for taking action to disrupt practices, policies, and pedagogies.

As the papers here make clear, the factors that prohibit diverse participation do not originate in and are not limited to what occurs in the classroom and curriculum. Even when the innovation focuses on classroom activities, they respond to a variety of administrative structures, campus climates, and policy environments, and they are written by individuals in a variety of roles: administrative, faculty, researcher. Shifting deeply entrenched structures requires innovation and the features of creative academic activism are not always fully invited into traditional research writing. "Close your eyes and think": even the voice of Nieminen and Valtteri Pesonen's comment is unusual in academic writing [1]. This collection of papers opens a wider space for higher education faculties to discuss how they organize their pedagogical or curricular choices with reference to the broader structures and systemic considerations that sometimes limit and sometimes enable faculty effort towards more inclusive higher education STEM programs. 


\section{Responses to Structures of Exclusion}

Systematic exclusion based on broad features of social inequality such as race, ethnicity, caste, economic status, disability status or the quality, accessibility, or tracking structures of public education at the primary and secondary levels is widely recognized [2-4]. Some countries, such as India and Brazil, use an affirmative action system in which seats are reserved for members of marginalized groups, with some tension over whether to emphasize amelioration of economic or racial inequalities. In the U.S. context, federal legal guidelines require equal educational opportunities regardless of a student's race, ethnicity, sex, national origin, or religion, but stop short of recommending reservation of seats at the point of admission for students from marginalized or minoritized groups.

The aspiration to serve students equitably is sometimes pitted against the need to claim competitive measures of quality such as research status or admissions selectivity, particularly in publicly funded universities in the U.S., a condition that Gonzales calls the "striving university" [5]. Faculty and other practitioner-scholars apply agency through negotiation, resistance, and critique, particularly when they wish to advance commitments towards civic engagement [5]. Our interest in this issue is to highlight ways in which higher education practitioners in STEM invest their agency in commitment to providing pathways that promote more inclusion and equity for students.

In considering the actions and reflections our authors highlight here, and their efforts to disrupt and intervene in structures of exclusion, we draw on linguistic anthropologist Laura Ahearn's intentionally flexible stance towards agency: "(a)gency refers to the socioculturally mediated capacity to act" [6] (p. 112). Ahearn defines agency as "a practice theory of meaning constraint" in which individuals or collectives create meanings using a variety of discursive, spoken, written or other multimodal resources [6] (p. 112). The papers in this collection represent STEM faculties finding the spaces in their sites of practices that offer the possibility of taking action by re-envisioning more inclusive STEM experiences in higher education.

Science, engineering, and technology courses often involve laboratory training, and for situations when this is organized around group rather than individual work, Leopold and Smith's paper makes a strong case for intentional support for effective collaboration [7]. Working from the standpoint of a high-enrollment General Chemistry laboratory course, they proposed efficient and achievable design features, "Group Check-ins," that help groups work together effectively. The Group Check-in innovation was designed to respond to disciplinary practices such as: high enrollments and group work focused on content delivery; national and university level policy documents that value the career-building potential of effective group work; and close attention to the time flow of class sessions that allowed incorporation of new, though brief activities without displacing course content.

Structures of exclusion may refer to literal and physical structures, as well as embedded ways of approaching and designing our courses. Nieminen and Valtteri Pesonen [1] considered both types of structures in reporting on a comprehensive revision of an introductory mathematics class at a Finnish university that was intended to remove barriers of physical or perceptual access. They reported on two studies that listened closely to students with disabilities as they navigated an undergraduate class in linear algebra that was substantially designed around Universal Design for Learning (UDL) and Universal Design for Assessment (UDA) principles. The authors expressed concern that research on UDL and UDA in undergrad STEM courses tends to focus on quantitative measurement of student learning, but without listening to students' own experiences. Even those qualitative studies that exist are not always clear about whether and to what extent students experienced classes that actually incorporated UDL. Nieminen and Valtteri Pesonen concluded that UDL/UDA should attend to its origins in social inclusion rather than medical framings of the need for inclusive classes. Only by attending to students' identity narratives were they able to notice that it is possible to have a UD math class that accomplishes "producing students who are highly capable of doing mathematics but only from the position of the excluded." [1].

Finally, structures of exclusion can include conventions in how we define core concepts in our disciplines. Maria Miriti challenged the concept of nature in ecology and environmental 
education-arguably one of the most important disciplinary concepts-and makes a case that this racializes these disciplines in ways that cannot be welcoming and sustaining for students who are racially and economically underrepresented in these disciplines [8]. Miriti also responded to processes of racial and ethnic exclusion in ecology and environmental sciences, but by taking on the broadest epistemological issues in her field of ecology, the problematic definition of nature as "remote and pristine with little influence from human activity," devalues experiences of nature in urban areas and is scientifically unfounded. The definition of nature, with embedded cultural biases, is an epistemological structure that is known widely in ecology and environmental sciences, and she argued that this way of thinking about nature is exclusive towards students of color and low-income students.

\section{Agency and Creative Action across Varied Domains}

The authors relate varied educational domains, across the levels of course assignments, modes of assessment, and enrollment levels; university, national and sometimes international educational policy statements; and widespread belief systems about disciplinary concepts such as "nature" or disciplinary pedagogical precepts such as individualism or collective engagement. Across these varied domains, we see that Ahearn's impression of agency as constrained practice [6] is animated by and through these chapters as the authors attend to the interplay of opportunity and constraints in ways that enable them to increase inclusivity and equity. At the postsecondary level, people take action from the domain in which they reside, but work towards inclusive higher education and typically must account for revision or response at multiple scales at once. It is not a matter of one domain being MORE important, but rather, a matter of each of us taking action and pushing against constraints from wherever we can and however they are.

Frequently, faculty and other practitioner-scholars have the greatest potential for action when they modify specific assignments or activities within a course. This smaller unit of action is delivered and completed relatively quickly, and so it might not require modification of many other components. By contrast, modifying institutional and national-level policies or broadly held disciplinary concepts requires more time and a wider scope of action than a single faculty group would typically possess. Science education researcher Jay Lemke captured this feature of agency through his theory of timescales [9]. In this form of analysis, short-term activities are somewhat (but not fully) constrained by the requirements of longer-term activities.

Below, we have summarized broad organizing principles, discourses, policies, or practices to which these authors have responded in trying to create more inclusive STEM education in their courses and programs. The authors note these organizing principles and their affordances and constraints as they make choices about how to disrupt exclusionary features of their workspace. I have arranged these in decreasing hierarchical order, which, according to Lemke's concept of timescales, could mean that the highest-level ones are the hardest to change and have agency within.

- Pervasive disciplinary concepts like "nature" (Miriti)

- Anglo-Eurocentrism (Miriti)

- Disciplinary pedagogical tendencies such as: large class sizes (Leopold and Smith; Nieminen and Valtteri Pesonen); disciplinary focus on individualism and content delivery (Leopold and Smith; Nieminen and Valtteri Pesonen); disciplinary expectation that group work is fundamental but groups are self-organizing (Leopold and Smith)

- International- or national-level policies like accessible higher education; academic freedom regarding course assessment, European Union statements (Nieminen and Valtteri Pesonen); higher education policy organizations like Association of American Colleges and Universities (Leopold and Smith)

- Professional conferences that contribute significant attention to STEM Exclusion, like the Cary Institute conference (Miriti)

- University-level expectations (Leopold and Smith) 
- University-level training for faculty in cultural competency, cultural humility, institutional support for new teaching approaches (Miriti); Faculty Learning Communities that create support structure for transformation (Leopold and Smith)

- Redesigning courses for better accessibility, support for student collaboration, course designers' reflective listening to not just content learning but students' ability to disrupt negative self-concepts, reflective practice research (Leopold and Smith, ieminen and Valtteri Pesonen).

- Time and space available in certain class sessions (Leopold and Smith)

- Modify specific assignments within a class (Leopold and Smith, Nieminen and Valtteri Pesonen)

As we reflect on the authors' innovations, we note a significant shared feature of their equity innovations: they choose actions that respond to multiple scales at once. Miriti, for example, recommends faculty development towards cultural humility in STEM to disrupt pervasive, global conditions of Anglo-Eurocentrism and scientific attitudes towards ecology. Small, immediate adjustments within a class session-changing an assignment or allocation of time to tasks-are constructed with responsiveness to national and international policy documents as well as to globally circulating disciplinary pedagogies (Leopold and Smith, Nieminen and Valtteri Pesonen). Higher education structures and practices are often slow to change even in the face of compelling needs such as improving access for underserved students. Faculty and instructional staff who wish to push their institutions towards equitable change may do well to follow the path of these peers, to learn to forge and to justify their actions across a similarly broad scope of action. These authors show that claiming and applying agency in higher education settings seems to require these scale-spanning conceptualizations.

\section{Conclusions}

When disciplinary research is at the center of faculty work, teaching innovation often becomes a secondary and undervalued form of labor. When higher education STEM faculties imagine better ways to engage more of their students, the opportunities to publish and disseminate their visions and revisions are limited. Arguably, there is a special element of craftwork to revisioning pedagogy, curriculum, and practice in our courses and program higher education revisioning, due to the short duration of courses compared to secondary levels and curriculum regimented by career pathways. Faculties must learn to support student learning experiences by balancing disciplinary expectations with national, institutional, and programmatic objectives. It is exactly this shaping of curricular activity across different scales that makes courses effective but that also makes it difficult to share models, because revisioning decisions may not immediately seem meaningful to others. However, because STEM courses are widely recognized as barriers to entrance and success in higher education settings globally (need cite), when higher education STEM faculties dedicate their attention towards the experiences of students who are undersupported in their programs, the need to share models of revisioning processes becomes even more important.

Author Contributions: Both authors contributed equally. All authors have read and agreed to the published version of the manuscript.

Funding: This research received no external funding.

Conflicts of Interest: The authors declare no conflict of interest.

\section{References}

1. Nieminen, J.H.; Valtteri Pesonen, H. Taking Universal Design Back to Its Roots: Perspectives on Accessibility and Identity in Undergraduate Mathematics. Educ. Sci. 2020, 10, 12. [CrossRef]

2. Ng, I.Y. Education and Intergenerational Mobility in Singapore. Educ. Rev. 2014, 66, 362-376. [CrossRef]

3. Pazich, L.; Teranishi, R. Comparing Access to Higher Education in Brazil and India using Critical Race Theory. Wide. Part. Life. Learn. 2014, 16, 50-69. [CrossRef] 
4. le Roux, K. Moving Up or Down the Ladder: University Mathematics Students Talk about Progress. In Mathematics Education and Life at Times of Crisis: Proceedings of the 9th International Conference of Mathematics Education and Society-MES9, Volos, Greece, 7-12 April 2017; Chronaki, A., Ed.; University of Thessaly Press: Volos, Greece, 2017; pp. 665-675.

5. Gonzales, L.D. Faculty Agency in Striving University Contexts: Mundane Yet Powerful Acts of Agency. Br. Educ. Res. J. 2015, 41, 303-323. [CrossRef]

6. Ahearn, L.M. Language and Agency. Annu. Rev. Anthropol. 2001, 30, 109-137. [CrossRef]

7. Leopold, H.; Smith, A. Implementing Reflective Group Work Activities in a Large Chemistry Lab to Support Collaborative Learning. Educ. Sci. 2020, 10, 7. [CrossRef]

8. Miriti, M.N. Nature in the Eye of the Beholder: A Case Study for Cultural Humility as a Strategy to Broaden Participation in STEM. Educ. Sci. 2019, 9, 291. [CrossRef]

9. Lemke, J.L. Across the scales of time: Artifacts, activities, and meanings in ecosocial systems. Mind Cult. Act. 2000, 7, 273-290. [CrossRef]

(C) 2020 by the authors. Licensee MDPI, Basel, Switzerland. This article is an open access article distributed under the terms and conditions of the Creative Commons Attribution (CC BY) license (http://creativecommons.org/licenses/by/4.0/). 